\title{
A Survey for Weather Communicators: Twitter and Information Channel Preferences $\mathscr{0}$
}

\author{
JOSHUA D. EACHUS AND BARRY D. KEIM \\ Department of Geography and Anthropology, Louisiana State University, Baton Rouge, Louisiana
}

(Manuscript received 28 August 2018, in final form 16 April 2019)

\begin{abstract}
It has been almost a decade since researchers assessed user preferences in gathering weather information. Maturing channels and increasingly mobile audiences necessitate the need for understanding what channels people use for weather information, what information people want, and how they react to specific contentespecially potentially life-saving warnings. Furthermore, geographically compartmentalizing this information will allow communication strategies to be tailored to a more localized audience. As an initiative to this effort, a survey of digitally connected Louisianians found different channel preferences than were found in previous studies. Beyond this study, future research should seek to identify regional preferences since the last broad study on this topic nearly 10 years ago. In the survey, information preferences are collected with Twitter as the focal point, but other channels are included as choices to assess overall user preference. As older channels such as television decline in preference, mobile telephone applications are disrupting previous literature by quickly gaining popularity while studies on their utility remain in short supply. Results show that user channel preferences do not necessarily align with those that best serve weather communication efforts. Facebook, a channel notoriously problematic from a chronology standpoint, is favored by many respondents. On Twitter, there is a disconnect in the type of information respondents report wanting and what type of information generates a response. Interest in warning messages was not coincident with the threat posed by that specific type of weather. The format-wording and construction-of warning messages that generated the most response on Twitter does not align with extensive literature on proper risk communication.
\end{abstract}

\section{Introduction}

The urgent nature of weather messages means that swift issuance is a top priority for communicators. Immediacy can allow the time needed for life-saving decision-making. However, immediacy has also become a priority for some information sources and used as a tool to create additional streams of advertising revenue. While competition has been healthy for the advancement of technology, it has been a hindrance to the spread of information.

Where a medium is a means of communication and a channel is a platform for transmission of information, postmodern electronic channels (those invented after

Supplemental information related to this paper is available at the Journals Online website: https://doi.org/10.1175/WCAS-D18-0091.s1.

Corresponding author: Joshua D. Eachus, joshua.d.eachus@ gmail.com newspaper, radio, and television) continue to accelerate the pace at which weather information is distributed. Through Twitter, Facebook and smartphone technology, most weather communicators are now able to reach an increasingly mobile society at any time of day. Weather messages need to be accurate, but also timely, making the rapid release and serial transmission capabilities of social media a perfect partner for weather communicators (Ferrell 2012).

However, when multiple sources converge on the same channel, there can be overlapping, conflicting, and inadequate information. Viral, Internet fame-seekers have also adopted social media to spread inaccurate but buzzworthy information. In addition, credible sources are also posting an array of content in the face of increasing competition. Furthermore, varying sources may be posting the same subject matter at the exact same time, but variations in wording could lead consumers to interpret different messages. Disagreeing forecasters may create more uncertainty for a follower trying to make a decision. Public and private entities may send warning 
messages providing varying levels of completeness. These postmodern electronic channels warrant intense scrutiny to optimize communication.

To date, no enforceable rules exists as to who can post weather information on social media. Responsible weather communicators may follow procedures recommended by guiding organizations. Beyond the realm of social media, weather communication practices may actually become more ambiguous. Under the larger umbrella of protecting life and property, the ultimate goals of the employing organizations drive weather communication practices. For instance, public- and private-sector meteorologists may be asked to communicate information in very different manners. Typically, government meteorologists are given a rigid set of guidelines for all public correspondence. On the other hand, the hundreds of private-sector on-air and online meteorologists have freedom from those guidelines and offer unique content and delivery style per their management teams.

Weather communication strategies on Twitter will be the focus of this study, as issuing sources should be asking several questions. What types of tweets does my audience want? To what types of tweets will my audience respond? Are weather warning tweets as effective as possible?

What is the preferred channel(s) for weather information? The most recent academic survey assessing American's channel preferences for weather information was issued in 2009, when television was still the top choice (Demuth et al. 2012). With many new channels gaining popularity since then, including Twitter, we must reevaluate where each stands. This study will examine user preferences and behaviors specific to Twitter and where the channel stands as a choice for information relative to others.

What types of weather information are wanted? Field leadership is recommending best practices for social media but more information is needed to leverage these strategies. To answer this question, survey respondents from Louisiana were asked to provide levels of interest in select channels and types of weather information. Additionally, preferences in watch/warning reception were evaluated using the example of a smartphone push notification. A general respondent understanding of terminology was also collected to gauge validity of answers.

What format of warning message on Twitter is most effective? Looking for interactions and therefore retransmission, we expand upon previous work(s) that contends that warning tweets structured with respect to the Extended Parallel Process Model (EPPM) will spread most effectively through a social network (Witte 1992; Hoang
2015). Each respondent was shown one of four example warning tweet formats and asked to select the level of interaction they would expect to have with that tweet.

After collecting pilot data, this study expanded the respondent pool to assess Twitter and other channels as tools for transmission of weather information and the EPPM as a guide for the formatting of weather watches and warnings on Twitter. In addition, a more robust survey allowed respondents to be sorted by various demographics including geographic location.

\section{Literature review}

\section{a. Pertinent communication theories and Twitter}

What format of warning message on Twitter is most effective? Having strong connections to various social networks, including Twitter, increases the chance one will receive a message (Donner et al. 2012). Twitter is one social network or channel available to those tasked with public safety and spreading warning messages. A well-constructed warning message may inspire protective action through a series of cognitive processes (Lindell and Perry 2012). Threat and efficacy frame the key components of an adequate warning message. Where weather threats are often communicated in terms of likelihood and magnitude, weather efficacy deals with an individual's ability to take protective action and the positive outcome that action could create (Hoang 2015). For simplicity, use of the weather efficacy in this research should be thought of as "action to be taken." Threat influences an individual's attitude and efficacy determines the positive or negative orientation of that attitude (Hoang 2015).

The Extended Parallel Process Model places the motivations of fear at the center of cognitive processing (Witte 1992). The model was developed in an attempt to predict an individual's response based on four inputs appealing to fear. The output, or response, is either fear control or danger control (Witte 1992). The EPPM has been applied in studies focused on antismoking and safe sex-predicting that messages communicating high threat and low efficacy will cause individuals to react to their own fear rather than the danger at hand (Hoang 2015). Although fear instigates maladaptive responses, when it is framed with efficacy then it can inspire productive and protective actions (Witte 1992). The EPPM underscores that one is coping with an event rather than escaping from an unpleasant emotional state (Hoang 2015). If responsible weather warning messages are intended to motivate protective action, one containing a clear representation of significant threat along with an achievable mitigating action could be reasoned as sufficient (Hoang 2015). 
As has been proven in the health community (Witte 1992), the EPPM may guide formatting of successful weather warning messages. Considering perceived susceptibility, perceived severity, response efficacy, and selfefficacy, an examination of national and local weblog (blog) posts prior to the landfall of Hurricane Ike found that many did not include all components. Additionally, threat components outweighed efficacy components, which according to the EPPM would cause fear rather than danger response processes (Gore and Bracken 2005). The research also found efficacy messaging showed up with decreasing frequency as landfall approached (Hoang 2015). While troubling, it is possible to reason from a meteorological and emergency response perspective that some actions simply can no longer be taken past a critical time.

The EPPM is certainly not without some oppositionas principles may not apply across the board. As is often the case, outcomes will vary based on the individual. In examining thresholds for proactive decision making based on probabilistic weather forecast information, research has found that messages delivered to inhomogeneous groups inspired different actions (Morss et al. 2010). With this outcome, it has been suggested that forecasts should provide information that can be acted on, such as probability and confidence, rather than specific actions (Morss et al. 2010). This would certainly leave room for some ambiguity in several components of an EPPM based message.

Geographical location has been shown to play a role in weather warning situations as well. Weather messaging should be tailored to specific communities, which are unique just like individual people. Rather than strictly scientific, consider a societal perspective to weather warnings (Donner et al. 2012). There has also been some survey work as to warning message wording and source (Perreault et al. 2014). Mock television tornado warnings were found to be more credible than radio warnings; however, the newest impact-based, high-threat, "scary" warnings were viewed as least credible (Perreault et al. 2014).

Messages indicating not only threat but also efficacy have been modeled and proven to have greater effect on proactive decision making (Hoang 2015). Many watches, warnings, and other urgent messages will present a threat or hazard without any action that can be taken to mitigate the risk. This often has counterproductive consequences, perhaps due to generating a helpless mentality (Lang 2000). Specifically in the era of storm-based warning polygons, not considering county and parish borders necessitates the need for a visual accompaniment. Pilot data for this research suggested a message providing threat, efficacy, and visual representation of a warning would be retweeted and told to others most. Unlike other channels such as television, radio, or newspaper, social media and Twitter are capable of providing a barrage of instantaneous information from a multitude of sources, simultaneously. While the timeliness and chronology of the information is beneficial, the user may be overwhelmed with content.

A concept known as social media fatigue (Bright et al. 2015) is worthy of consideration as Twitter is evaluated as a weather information channel. The Limited Capacity Model (LCM) (Lang 2000) states that people have a limited amount of mental resources to process information. Under the assumption that people are information consumers with a limited capacity to do so, people must make compromises as distractions will limit attention to and retention of information (Lang 2000). Recall and comprehension are also adversely affected by an overabundance of information (Bright et al. 2015). Although this study is not geared toward evaluating the LCM, its merits are at least peripheral to this area of study and should be given consideration as an encumbrance to weather communication.

Some weather events lead to more social media volume than others. This verifies that even somebody with a small but homogenous, or weather-centric, social network could be inundated with information (Hong et al. 2011). Those weather events that forebode greater impact to society generate a greater need for information and an increase of information flow. Congruently, these events demand a greater need for well-communicated information, but it is unclear whether this need is being fulfilled.

\section{b. Weather information and Twitter}

Practices recommended by the American Meteorological Society (AMS) and National Weather Association (NWA) have good faith intentions (AMS 2017; Bunting and Muzio 2014), but outcomes still have varying levels of success. Steps have been taken to guide behavior of those communicating weather online (AMS 2017). In a detailed statement from AMS, practitioners are advised on how to represent forecast model data and uncertainty, to construct headlines, to offer schedules of updates, and to relay appropriate NWS products as well as pertinent climate data (AMS 2017). With regard to social media, practitioners are urged to offer specificity in abilities of given forecast products and the associated timeframe (AMS 2017). The NWA has even gone as far as offering a digital seal of approval program coexistent with broadcasting seals of approval (Bunting and Muzio 2014). However, these are simply recommendations and there is no true governance of how, when, and why content is posted. There has been work to understand 
the key components of a successful message (Lindell and Perry 2012; Trainor and McNeil 2008) with modern electronic channels like print, radio, and television broadcasting. However, multiple studies have identified that Internet users find web sources to be just as credible as, if not more credible than, modern channels such as traditional print, radio, and television (Johnson and Kaye 2004; MacDougall 2005). If that perception exists, practitioners must take the postmodern electronic mediums seriously as delivery channels. Social media, and specifically Twitter, are no longer tertiary tools. It is time to optimize the 280-character message-often the first place where big weather messages are brought into existence.

\section{c. Popular weather content among Twitter users}

What types of weather information are wanted? As of January 2016, the Pew Research Center reported that $21 \%$ of adult Americans use Twitter and $42 \%$ of users check it daily (Greenwood et al. 2016). In addition, Internet estimates are that more than 500 million unique tweets are sent on a daily basis. More specific to this study, Twitter has been gauged as a metric for heightened attention from the general public during severe weather (Ripberger et al. 2014). This was asserted as a 6-month, 1.7-million-account analysis found that less than $6 \%$ of these users were frequent commenters on severe weather, yet their volume usage of the word "tornado" showed a spike on days with high numbers of weather watches and warnings (Ripberger et al. 2014). Having this insight places Twitter among other media as player worthy of study in weather communication.

Case studies have found reporting (secondhand) information as the main use of Twitter during impact weather (Takahashi et al. 2015). Even by segmenting populations of the dataset, and eliminating journalists, important information was still transmitted. Individuals used the channel for reporting $33 \%$ of the time and for memorializing affected people and communities $55 \%$ of the time (Takahashi et al. 2015). While exact usage numbers within the full population remain unknown, these statistics suggest that a significant segment of the population is using Twitter during impact weather events.

Previous studies have analyzed large datasets of tweets and/or hashtags to identify patterns in content during disasters or impact weather events (Lachlan et al. 2014; Kogan et al. 2015; Romero et al. 2011; Verma et al. 2011; Bruns and Burgess 2011; St. Denis et al. 2014). Geographical differences among tweets and users have been a focus. Local sources such as government and media tended to provide more useable information for Twitter users (Lachlan et al. 2014), and those being affected by disasters were the most active during the event while also providing and propagating information (Kogan et al. 2015). While findings from these studies are important to weather communication strategies, they may only be a part of the puzzle. Lacking in the literature is recent survey work on what Twitter users self-report about their habits and desires from Twitter with regard to weather.

\section{d. Recent surveys}

What is the preferred channel(s) for weather information? Twitter and other social media channels barely registered as a choice for consumers in the most recent studies identified. As of 2006, a poll of 1465 people from every U.S. state and Washington, D.C., aimed to learn about preferences from Americans that chose to get a daily weather forecast. The authors report a survey sample that had a gender and race distribution similar to that of the U.S. public. However, it was skewed to be slightly older and more educated and mostly of middleclass income (Lazo et al. 2009). The work found timeframes for which consumers wanted forecasts, weather details they found important, events and locations for which forecast information was desired, and overall confidence in aspects of a forecast. Particularly pertinent to our study the 2006 survey found that a majority was getting once daily weather forecasts from local television $(36 \%)$ and newspaper $(24 \%)$ instead of the National Weather Service (Lazo et al. 2009). Researchers then noted that growing digital space would likely change the way people consume weather forecasts and subsequent studies should be conducted to track weather information consumption on these channels. The team also expressed a need to look at in-depth topics like communication of warnings (Lazo et al. 2009).

In 2010, as part of an assessment on the National Weather Service website, a research team included a few new channels that could be used to consume weather forecast information. A sample of over 1200 respondents reflective of the United States population scored websites, NOAA weather radio, local television, local radio, and smartphones all as somewhat useful. Interestingly, only websites scored somewhat useful with regard to meeting respondent needs for weather information (Demuth et al. 2012). For a daily forecast, television remained the primary channel preference with $44 \%$ of respondents consulting either local or cable networks at least once daily (Demuth et al. 2012). Newspaper and websites each were reportedly checked once daily by $19 \%$ of respondents. Fewer than $9 \%$ of respondents consulted mobile telephones and social media more than once per day for their forecast (Demuth et al. 2012). Still, aside from inclusion on the survey with other minority preferences, there was no 
trend of increasing usage with postmodern electronic channels for weather information.

As compared with 2006 and 2009, when the last similar surveys were taken, modern mediums, or channels, such as television, radio, and newspaper are now delivering information in tandem with postmodern electronic mediums, or channels, such as social media and smartphones. We suspect the preference for television as a weather information source will be lower in subsequent survey reports. Furthermore, a category unavailable in 2009_-the smartphone application-may capture some percentage of the channel preference.

\section{Methods}

To understand weather information preferences of a large and diverse population, surveys are a common research approach (Lazo et al. 2009). To first identify need for a full-scale survey, we administered a pilot survey that collected data from 50 respondents, 45 of whom were female, ages 18-26, attending a large university in the southeastern United States. Respondents were asked to gauge their interest in specific channels. Via example tweets, they were also asked to scale interest in specific types of content and then were shown examples of content types to see whether "self-reported" interest levels matched interactions with example content. Findings of the pilot survey suggested no parallel between ranked interest and interaction. While people may want a daily forecast, it may not be something they are likely to retweet or tell others. While people may not want warnings, the urgency of such messages may inspire interactions-retweeting, telling others, and clicking a link for more information. Twitter was not ranked as a highly preferred channel for weather information but when used as a delivery mechanism for warning messages, those containing threat and efficacy were most likely to be retweeted. The pilot survey began an investigation as to the effectiveness of the Extended Parallel Process Model as a guide for warning messaging on Twitter. Limitations from the pilot study such as an intentionally small respondent pool and even smaller pool of frequent Twitter users necessitated the need for broader study. The pilot study also provided guidance on how to improve the structuring of survey prompts to and research questions.

In this particular survey, the focus is on Twitter as a weather communication channel. Respondents were asked to rank their channel preferences, which were limited to those commonly provided by broadcast media outlets. Those included television, website, Facebook, Twitter, and mobile telephone application (app). In addition to collecting some demographic information, questions also assessed respondent understanding of weather watch and warning terminology as well as the specific hazards for which they want information.

Question design was optimized through consultation with experienced weather-related survey administrators at the University of Alabama-Huntsville and California University of Pennsylvania. Created and administered through the Qualtrics company, the survey was pretested with people who were not considered to be weather communicators as one final quality check for clarity. The full survey can be found in the online supplemental material.

Surveys were distributed via the social media accounts and websites of colleagues in meteorology, climatology, and emergency management. An e-mail was sent to each broadcast meteorologist listed on local television station websites and each office of emergency management in the state of Louisiana. Several NWS meteorologists also shared the links on their personal social media accounts. For those willing to take part in distribution, a link to the survey was provided along with suggested prompts for websites, Facebook, and Twitter. While Internet reach inevitably extends beyond a confined geographic area, survey design consultants advised partitioning response data by state to allow geographic homogeneity when evaluating results and making recommendations to practitioners. Of course, using social media and Internet platforms as a distribution tool can be prohibitive to collecting a full sample of the population. In this case, we specifically aim to understand the habits of people who are not in a weather related field that have access to both postmodern traditional and modern channels. Several qualifying and demographics were posed to open the survey to help achieve this sample.

A popular method in social sciences, the Likert scale was developed in 1931 to assess attitudes (Croasmun and Ostrom 2011). For several questions, we used the Qualtrics survey software to calculate a mean score. These scores indicate overall respondent rankings. As a 1-5 ranking scale was used throughout the survey, higher scores lean toward 5, which was the affirmative ranking, and lower scales lean toward 1, which was the negative ranking.

To assess the preferred channel(s) for weather information, the first section of the survey assessed respondent reasoning for following weather accounts on Twitter and preferences in getting a weather forecast. Respondents arranged and ranked a list of five channels for weather information and for weather watches and warnings. To build on these insights, the next series of questions gathered respondent understanding and preferences with weather watches and warnings. Notably, respondents were asked to select watches 
and warnings that they want to know about and/or receive push notifications to their mobile devices.

The final sections of the survey contained example tweets; a series of Twitter images was designed. The images were created by using an original Twitter message as a template and then altering the content in Microsoft Paint using Twitter's Arial font. Associated weather images were designed using the Weather Services International (WSI) Max graphic suite. Weather information pertained to a geographic location that was nonspecific to the target survey audience of Louisiana residents. To avoid any biases, no identifying "source," such as a television station or the National Weather Service, was provided.

To assess what types of weather information are wanted, mock tweets of four varying content types-forecast, explainer, watch, and photograph-were shown to respondents. To assess interactions with types, respondents rated their likelihood to retweet, tell others, scroll past, or click a link associated with the message.

To assess what format of warning message on Twitter is most effective, mock warning tweets were provided with four varying message formats. One format contained threat and weather efficacy with a picture, one contained threat in only text, one contained threat with an image, and one contained only weather efficacy. These tweets, used to test the EPPM components of threat and efficacy, were not shown to the entire survey segment. Rather, the four messages were evenly and randomly distributed among the respondents to avoid any comparative biases or priming. Again, to assess interactions by warning format, respondents rated their likelihood to retweet, tell others, scroll past, or click a link associated with the message.

Qualtrics survey software provided the total number of responses and percentage of total response given to each answer. By exporting the results to Microsoft Excel, mean scores were tallied for each choice on the survey. The means were used to rank most to least popular as well as a relative scale among choices. These data are available in raw form in the online supplemental material, and the analyzed data are provided in graphical and tabular form through the results.

\section{Summary of results}

From 23 March to 1 August 2017, the survey collected 276 completed responses. Sixteen respondents answered that they worked in meteorology or climatology, and they were excluded for possible pre-existing biases and insights to the questions. A total of 47 respondents were not from Louisiana and these were not retained in this analysis. However, these surveys will be kept for analysis of other states in a later study. In total, 196 surveys remained for analysis. A total of 69 males and 127 females ranging in age from 18 to $65+$ completed the survey. The entire survey report is provided in the online supplemental information. Not all respondents answered every question, so total responses for any given question will be equal to or less than 196. We analyzed the results in four sections-weather information channel preferences, information desired, watches and warnings information, and warning format.

\section{a. Weather information channel preferences}

Before making any efforts at message optimization, those providing weather information need to know the preferred channels of forecast users. Respondents $(N=166)$ were asked to rank five channels from most preferred (5) to least preferred (1) for getting weather information. Table 1 shows a summary of responses, from most preferred (5) to least preferred (1) including the number of times $n$ each channel was chosen as a ranked preference as well as the percentage relative to other channels. Interestingly, telephone applications were both the most common top choice and the most common last choice. A few of the write-in submissions for the channel "other" included newspaper $(n=1)$, NOAA Weather Radio $(n=1)$, radio station $(n=1)$, and text message $(n=1)$.

Unlike 2006 and 2010 surveys (Lazo et al. 2009; Demuth et al. 2012), mean scores of first choices, postmodern electronic channels (telephone app, Facebook, and Twitter) were preferred over modern electronic (television) channels. Including the mean score of each channel for all responses ranks the channels from most to least preferred as website, Facebook, television, Twitter, telephone app. Telephone apps did claim most of the top-choice preference at $23 \%$ but also had most of the last-choice preference at $30 \%$, which was enough to skew it to last place overall.

\section{b. Weather information desired on Twitter}

On the same 1-5 Likert scale, more than $80 \%$ of respondents agree or strongly agree that they want to have a weather forecast updated every day $(n=137)$ (Table 2). When asked about reasons for following weather accounts on Twitter, mean scores showed watches and warnings as the most likely reason $(n=114)$ and photographs and videos as the least likely reason $(n=$ 50) (Table 2).

In a later section of the survey, respondents were shown example tweets for each of the four message types in Table 2. They were asked to rank the likelihood for each tweet type that they would retweet, tell others, scroll past, or click a link. Watch and warning tweets and 
TABLE 1. Respondent rankings of weather information channel preferences. Columns display percentage of total responses and total number of responses for each channel and ranking. Mean overall ranking is shown in the last column.

\begin{tabular}{|c|c|c|c|c|c|c|c|c|c|c|c|}
\hline \multirow{2}{*}{$\begin{array}{l}\text { Channel } \\
\text { Twitter }\end{array}$} & \multicolumn{2}{|c|}{ Fifth choice } & \multicolumn{2}{|c|}{ Fourth choice } & \multicolumn{2}{|c|}{ Third choice } & \multicolumn{2}{|c|}{ Second choice } & \multicolumn{2}{|c|}{ First choice } & \multirow{2}{*}{$\frac{\text { Mean }}{2.93}$} \\
\hline & $29.70 \%$ & 49 & $15.76 \%$ & 26 & $15.15 \%$ & 25 & $13.94 \%$ & 23 & $18.79 \%$ & 31 & \\
\hline Television & $12.12 \%$ & 20 & $29.70 \%$ & 49 & $20.00 \%$ & 33 & $18.79 \%$ & 31 & $17.58 \%$ & 29 & 3.05 \\
\hline Facebook & $18.79 \%$ & 31 & $15.76 \%$ & 26 & $18.18 \%$ & 30 & $21.21 \%$ & 35 & $22.42 \%$ & 37 & 3.24 \\
\hline Website & $6.06 \%$ & 10 & $18.79 \%$ & 31 & $32.73 \%$ & 54 & $27.88 \%$ & 46 & $12.73 \%$ & 21 & 3.28 \\
\hline Telephone app & $30.30 \%$ & 50 & $16.97 \%$ & 28 & $12.73 \%$ & 21 & $15.15 \%$ & 25 & $23.03 \%$ & 38 & 2.89 \\
\hline Other & $3.03 \%$ & 5 & $3.03 \%$ & 5 & $1.21 \%$ & 2 & $3.03 \%$ & 5 & $5.45 \%$ & 9 & \\
\hline
\end{tabular}

photograph tweets had higher scores for respondent interest (Table 2) than for respondent favorable interactions (retweet, tell others, click link) with example tweets (Table 3). Respondents also demonstrated a lower interest in a general forecast tweets than what was self-reported in Tables 2 and 3.

Respondents indicated that receiving a daily weather forecast was important to them. As expected though, respondents' mean scores were between strongly disagree and disagree for likelihood to retweet, tell others about, or click a link on a tweet of a daily forecast. Respondents agreed that they followed Twitter accounts for watches and warnings and the mock watch tweet did receive the highest mean score for likelihood to retweet and likelihood to tell others.

Photograph tweet interactions scored higher than selfreported interest in such tweets. The mean score for interactions with the mock photograph tweet were lower than self-reported interest in weather photographs.

\section{c. Watches and warnings}

Before analyzing the effectiveness of different formats of warning tweets, we gathered a general assessment of respondent understanding of weather watches and warnings. Responses indicate that $94.2 \%$ and $94.8 \%$ respectively matched "have a plan in place" and "significant weather may occur at a later time" with the term "watch." Also, 96.1\% and 94.8\% respectively matched "take action now" and "significant weather is occurring" with the term "warning." All except one respondent reported being under a weather warning within one year of taking the survey. This respondent must not have gotten notification as the Iowa Environmental Mesonet shows that every parish in Louisiana had been under some sort of weather watch or warning during the one-year period (IEM 2017). A total of $87.9 \%(n=147)$ of respondents said they took action as a result of a warning within the last year.

A total of $92 \%(n=150)$ of respondents said that they like to have watches and warnings as soon as they are issued. Respondents were also asked to rank channel preferences for getting watches and warnings. Television had the highest mean score followed by website, Facebook, telephone app, and Twitter (Table 4).
Respondents were asked what watches and warnings they want to know about and then for what watches and warnings they would like push notifications to their mobile telephones (Figs. 1 and 2). A total of 166 of 167 wanted to know about tornado warnings, and 161 said they would like a push notification to their mobile telephone in the event of a tornado warning. More than $75 \%$ of respondents also would like to know about severe thunderstorm warnings $(n=161)$ and flash flood warnings $(n=137)$, but a slightly lower percentage want those warnings pushed to their mobile telephones. While nearly one-half of respondents want to know about river flooding, winter storms, extreme temperatures, and dense fog, less than $30 \%$ want those alerts pushed to their mobile telephones.

\section{d. Warning format}

At the end of the survey, each respondent was randomly shown one of four possible warning formats. Responses produced unexpected results, contrary to data from the pilot survey and contrary to what literature suggested we would find (Table 5). The warning tweet format most likely to be retweeted was threat only with just text. The warning tweet format that respondents would most likely cause them to tell others was threat only with a graphic included. The warning tweet format expected to score best, threat and weather efficacy with a graphic, was the least likely to be retweeted and the second least likely to cause respondents to tell others.

TABLE 2. Respondent rankings of weather information preferences: the mean score goes from 1 (strongly disagree) to 5 (strongly agree).

\begin{tabular}{lc}
\hline \hline \multicolumn{1}{c}{ Prompt } & Mean \\
\hline Preferences in getting a weather forecast & \\
Updated every day & 4.31 \\
Only when the weather is threatening & 2.99 \\
I follow weather accounts on Twitter because... & Mean \\
I need to have a forecast & 3.75 \\
I am interested in weather & 3.80 \\
I want watches and warnings & 4.43 \\
I want pictures/video of nature and weather & 3.40 \\
\hline
\end{tabular}


TABLE 3. Mean scores of respondent response to example tweet types.

\begin{tabular}{lcccc}
\hline \hline & Retweet & Tell others & Scroll past & Click link \\
\hline Forecast & 1.41 & 1.92 & 3.13 & 1.86 \\
Explainer & 2.25 & 3.03 & 2.09 & 3.13 \\
Watch & 2.30 & 3.24 & 2.07 & 3.06 \\
Photograph & 1.88 & 1.74 & 2.70 & 1.99 \\
\hline
\end{tabular}

\section{Discussion, limitations, and future study}

\section{a. Discussion of results}

Results of this survey have identified a number of topics worthy of further discussion and research within the weather enterprise. Before positing those topics, we will examine results of the three primary questions asked prior to this research and provide some rationale.

\section{1) WHAT ARE THE PREFERRED CHANNELS FOR WEATHER INFORMATION?}

Previous surveys (Lazo et al. 2009; Demuth et al. 2012) found television to be the favored channel but anticipated a shift as new technology emerged. Indeed, this survey suggested websites, Facebook, and television, in that order, as the top three choices for consumption of weather information, albeit with a very narrow gap. Sorting for age did not reveal any significant trends. Despite having spent a larger portion of their adult lives without postmodern electronic channels, older respondents showed no less preference for these channels than did younger respondents.

Overall, in the United States, Facebook has approximately 3 times the number of users as Twitter (Salinas 2018). While it may be argued as reasoning for the rankings, a prerequisite of this survey was that the respondent was a Twitter user. These results tell us that even if the user is on both channels, Facebook seems to be preferred, at least for weather. The relatively high respondent affinity for Facebook is somewhat unsettling from a weather information perspective. Facebook is designed to place popular, and not necessarily timely, content in user timelines. Those responsible for sharing weather information should post to Facebook carefully, making sure dates and times are a clear part of any such content to avoid misrepresentation.

Meteorologists may argue that Twitter has an advantage over websites, Facebook, and television because it still allows a consumer to be mobile while seeking information via the channel's smartphone interface. In addition, one can chose to receive notifications when a selected weather source tweets information, such as a preferred weather source. While Facebook may be configured similarly, from a content-seeking standpoint there are still algorithm issues. With the exception of a recently added "in case you missed it" section atop timelines (a feature that can be turned off), Twitter displays information chronologically, meaning that the latest information will be seen first. While continued public awareness of these features may be beneficial, it is important to know, at this time, that not all consumers will choose to use Twitter, and ample focus should be dedicated to refining communication strategies on other channels.

\section{2) WHAT TYPES OF WEATHER INFORMATION ARE WANTED?}

The survey consensus was that people wanted a daily forecast but follow weather accounts on Twitter for watches and warnings. This peripherally coincides with the finding that weather Twitter traffic increases on days with severe weather (Ripberger et al. 2014). Expressed interested in photographs was lower than expected. While we would not necessarily expect people to tell others about a photograph they saw, or click a link when a photograph is the key piece of information, photographs were the most retweeted content in previous research and pilot studies (Eachus 2017). The lack of interest in tweets containing photographs may have been tied to the example content. The mock tweet photograph of a sunset may have been underwhelming in comparison with highly retweeted photographs of tornado and flood damage in previous case studies. Additionally, the proven affinity for local content was not met (Trainor and McNeil 2008; Lachlan et al. 2014).

TABLE 4. Respondent selections of weather watches and warnings channel preferences. Columns display percentage of total responses and total number of responses for each channel and ranking. Mean overall ranking is shown in the last column.

\begin{tabular}{|c|c|c|c|c|c|c|c|c|c|c|c|}
\hline \multirow{2}{*}{$\begin{array}{l}\text { Channel } \\
\text { Twitter }\end{array}$} & \multicolumn{2}{|c|}{ Fifth choice } & \multicolumn{2}{|c|}{ Fourth choice } & \multicolumn{2}{|c|}{ Third choice } & \multicolumn{2}{|c|}{ Second choice } & \multicolumn{2}{|c|}{ First choice } & \multirow{2}{*}{$\frac{\text { Mean }}{2.80}$} \\
\hline & $35.03 \%$ & 55 & $17.83 \%$ & 28 & $9.55 \%$ & 15 & $12.74 \%$ & 20 & $19.11 \%$ & 30 & \\
\hline Television & $8.28 \%$ & 13 & $25.48 \%$ & 40 & $23.57 \%$ & 37 & $20.38 \%$ & 32 & $17.20 \%$ & 27 & 3.28 \\
\hline Website & $3.82 \%$ & 6 & $22.93 \%$ & 36 & $35.03 \%$ & 55 & $25.48 \%$ & 40 & $12.74 \%$ & 20 & 3.20 \\
\hline Facebook & $14.65 \%$ & 23 & $18.47 \%$ & 29 & $22.29 \%$ & 35 & $22.29 \%$ & 35 & $21.02 \%$ & 33 & 3.20 \\
\hline Telephone app & $34.39 \%$ & 54 & $12.74 \%$ & 20 & $8.28 \%$ & 13 & $16.56 \%$ & 26 & $24.84 \%$ & 39 & 2.94 \\
\hline Other & $3.82 \%$ & 6 & $2.55 \%$ & 4 & $1.27 \%$ & 2 & $2.55 \%$ & 4 & $5.10 \%$ & 8 & \\
\hline
\end{tabular}




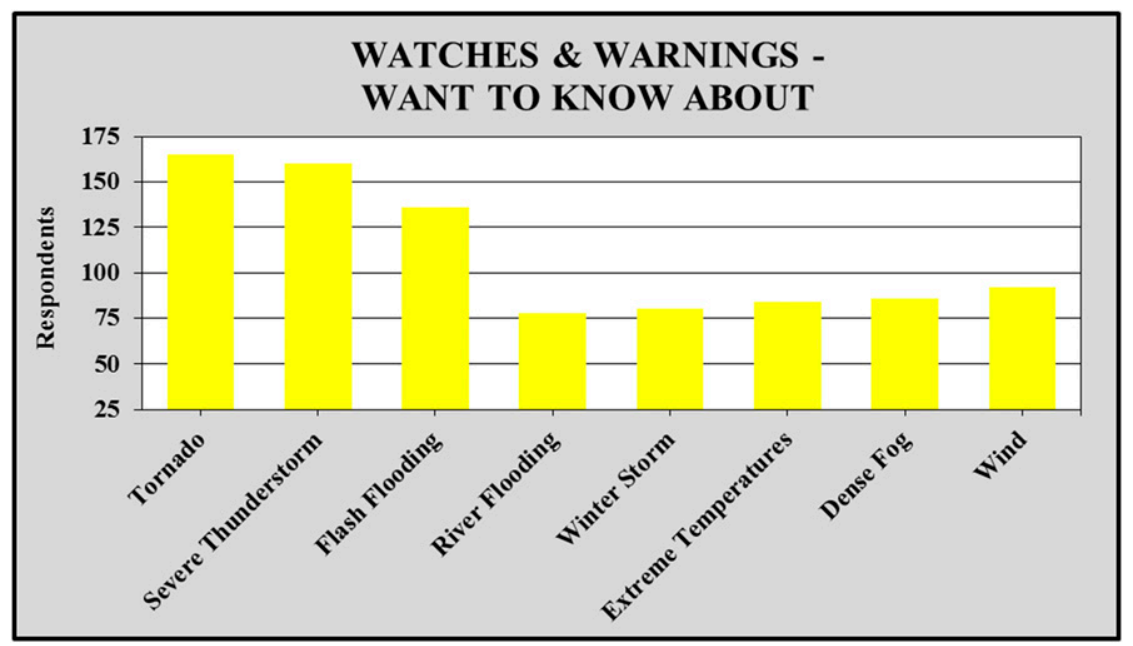

FIG. 1. Respondent selections of watches and warnings about which they want to know.

Information that respondents reportedly want and information to which they react send mixed signals. When provided with definitions and terms associated with both weather watches and warnings, more than $95 \%$ of respondents were able to correctly drag and drop the definitions and terms next to the corresponding word, representing some understanding of the subject. Respondents weighted interest in tornado, severe thunderstorm, and flash flooding alerts well above that of others presented. However, across the board, respondents scored knowing about an alert higher than wanting a push notification to their mobile device for that alert.

These findings are consistent with the challenges presented by mobile telephone apps and lend important insight to weather communicators. Even a digitally inclined sample of the population may become apathetic with an overabundance of alerts, causing desensitization or perhaps cry-wolf syndrome (Barnes et al. 2007) to decrease effectiveness of future alerts. A push notification is currently the most intrusive form of channel to receiver communication. Through the NWS Wireless Emergency Alert system, or any private-sector mobile weather application, a watch or warning may be forced to a device. Somebody away from home, away from television, or even away from a computer may be interrupted with an alert. While this has clear, potentially life-saving benefits, especially private-sector weather communicators need to consider the ramifications of overuse. For instance, if an application pushes less threatening alerts for dense fog and wind, perhaps a

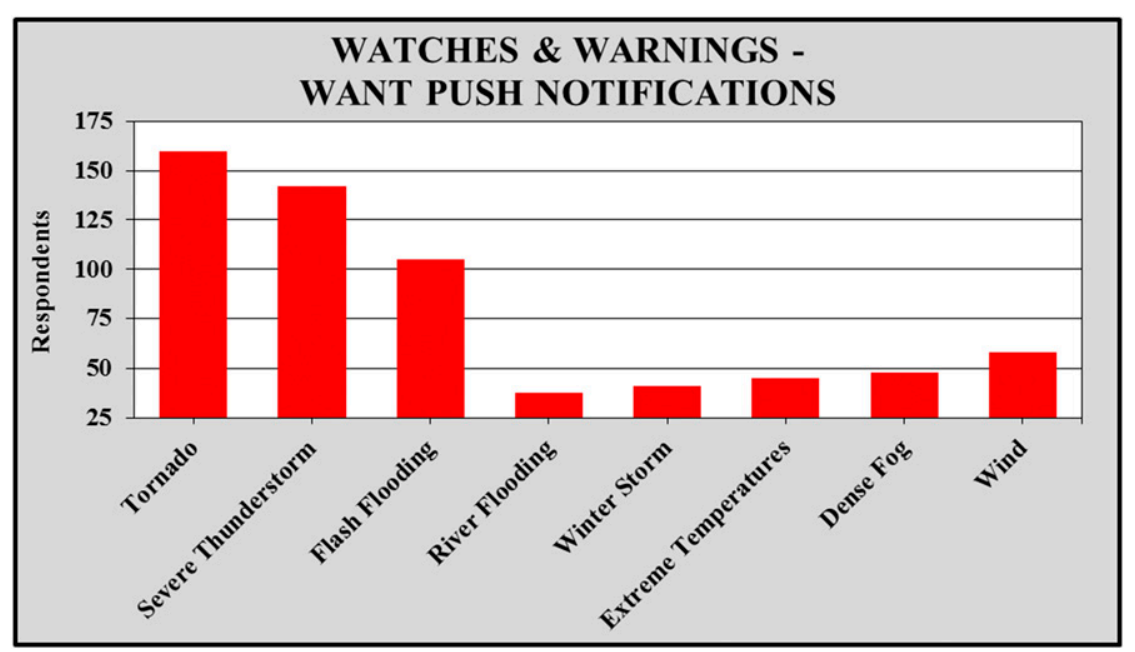

FIG. 2. Respondent selections of watches and warnings for which they want push notification to their mobile telephone. 
TABLE 5. Mean scores of respondent response to example warning tweet formats; $n$ gives the sample size.

\begin{tabular}{lcccc}
\hline \hline \multicolumn{1}{c}{ Warning format } & Retweet & $\begin{array}{c}\text { Tell } \\
\text { others }\end{array}$ & $\begin{array}{c}\text { Scroll } \\
\text { past }\end{array}$ & $\begin{array}{c}\text { Click } \\
\text { link }\end{array}$ \\
\hline $\begin{array}{l}\text { Threat, efficacy (graphic) } \\
\quad(n=33)\end{array}$ & 2.79 & 4.09 & 1.64 & 3.27 \\
Threat only (just text) $(n=38)$ & 3.51 & 4.23 & 1.51 & 4.03 \\
Threat only (graphic) $(n=39)$ & 3.37 & 4.33 & 1.47 & 4.37 \\
Efficacy only (graphic) $(n=44)$ & 2.93 & 3.98 & 1.80 & 3.66 \\
\hline
\end{tabular}

user will not react to the indication or read the bulletin when a more life-threatening tornado warning is pushed through.

Fewer than $70 \%$ of respondents wanted push notifications for flash flooding, yet over $80 \%$ of respondents wanted push notifications for severe thunderstorms and up to $90 \%$ for tornadoes. The lower percentages that wanted push notifications for flash flood warnings or extreme temperatures suggests a lower dread factor (Slovic et al. 1982) associated with these hazards — which each have killed more people per year in the United States on a 30 -yr average than tornadoes, wind, or lightning (NWS 2016). Fewer than $30 \%$ of respondents wanted push notifications for temperature-related hazards, which have also produced mass fatalities as in the Chicago heat wave of 1995.

Telephone app was also polarizing in the ranking preferences for receiving watches and warnings, having the most first-choice rankings and also the secondmost (by one vote) last-choice rankings. Twitter had the most last-choice rankings. Combined, telephone app and Twitter accounted for approximately $50 \%$ of the fourth- and fifth-choice rankings. Because so much emphasis is placed on pre-event education about weather events (Trainor and McNeil 2008), weather communicators should also consider more outreach and awareness for channels like the telephone apps and Twitter. They are arguably the timeliest in distributing information. While we just considered potential pitfalls of telephone apps, when used correctly they certainly are capable of being the first channel to deliver information to a large segment of the population who may not be actively searching for weather watches or warnings. Consider the alternatives; television, websites, Facebook, and even Twitter require one to be actively using that channel to receive the information. In many cases, some form of secondary human intervention is needed to initiate watches and warnings on these channels as well. Apps are typically triggered instantaneously via the primary NWS issuance. Some sources also have arrangements that automatically transmit watches and warnings to the other channels but again, a person must be actively using that channel to receive a warning.

\section{3) WHAT FORMAT OF WARNING MESSAGE ON TWITTER IS MOST EFFECTIVE?}

The verbiage that generates attention or reaction to a warning is still unclear. This topic is most worthy of further scrutiny as it affects weather messaging, possibly on all channels. Most literature with respect to the EPPM would suggest that the most effective format for a warning message would include threat, weather efficacy, and some way of personalizing a message-such as a map of the threatened area (Witte 1992; Hoang 2015). Examination of actual events has shown receiver preference for the properly formatted warning tweet with threat, weather efficacy, and an image (Eachus 2017). Why, then, did that message format not yield the most favorable interactions (likelihood to retweet, tell others, click link)? It is possible that the example tweets were not personal enough. Perhaps Louisiana respondents did not empathize with a tornado warning for the Philadelphia area-selected as a geographically neutral location for the survey. It is possible that respondents from Louisiana assumed geographic insularity and if they knew nobody from the Philadelphia area that would be affected by the tornado warning, then they would have no reason to spread that warning message through their social network or gather more information. Furthermore, it is possible that knowing they were not actually affected, there would be no reason to share the tweets containing actionable information. Last, the idea that an inhomogeneous group of individuals reacted differently to the same message (Morss et al. 2010) is not a far leap in logic. Despite sound reasoning (Hoang 2015), it is yet undetermined if the EPPM is an effective model to communicate risk in weather scenarios as it has shown to be in healthcare (Witte 1992).

Threat-only tweets had high mean scores for both likelihood to retweet and likelihood to tell others. While warning communicators may see this as a route to take for warning formatting, one should interpret the results with caution. By issuing a threat-only statement and having that message retransmitted through a social network, we are assuming that message receivers know the proper mitigation strategies for that threat. We must remember that a retweet of a threat-only message could be a reaction to fear rather than danger, which is often a much less rational process (Witte 1992). This could produce similar, possibly deadly, results in taking action on the warning.

\section{b. Limitations and future study}

While this survey could stand to benefit from a larger respondent pool, it was intentionally limited geographically to allow cross comparison and expansion of 
localized weather communication research. State-bystate or even city-by-city surveys may help weather communicators to understand the needs of their populations. Distribution methods could be altered to achieve a desired sample of the population. Surveys like this should be performed more often (Lazo et al. 2009) and more regionally. Weather communicators would benefit from understanding changes in channel preference over time and geographically. It is possible, if not likely, that Midwest residents would react differently to tornado warnings than Gulf Coast residents. It is also possible that Midwest residents' perceptions of tornadoes have changed with time.

In this case, because we aimed to understand more about Twitter as a weather information and weather warning channel, survey distribution primarily on social media likely yielded a more digitally fluent respondent pool. It is possible though that this distribution method reached an audience less inclined to rely on television as an information channel. Therefore, speculation about preference for television as a weather information channel of the population may be reserved for another study with an alternate distribution method.

Similar to work done by Lazo et al. (2009) and Demuth et al. (2012), research could go beyond simple channel preferences and incorporate situational channel preferences. For instance, researchers may examine when people prefer television to a website, what type of weather information people prefer on Facebook versus Twitter, and how different segments of the population are using these channels. We also encourage similar studies on warning formatting on Twitter and other channels. Warnings are the most critical weather messages regarding protection of life and property and should be prioritized in studies as such.

Twitter has become a vast social network where many lifestyles interact on the same playing field. Among many subgroups, there is the weather expert and the layperson. Of course, there is little limitation as to whom one can follow. A layperson highly interested by but not necessarily formally educated about weather could follow a very large number of weather-related accounts. It is also likely that many of these weather accounts are tweeting conflicting or confusing information and jargon. Natural competition for social equity and peer approval on Twitter may lead to conversations and content that cause one to lose trust in weather communicators or misinterpret information. Inevitably, some weather events will lead to more Twitter content than others. This allows a presumption that even somebody with a small but homogenous, or weather-centric, social network could be inundated with information (Hong et al. 2011). The volume of use during high-impact weather could be making Twitter its own obstacle to effective information spread.

Under the assumption that people are information consumers with a limited capacity to do so, there must be compromises as the amount of data continues to overwhelm available attention (Lang 2000). While this study did not test particularly for social media fatigue, the concept is significant enough that it may be considered by future research specifically with regard to weather information on Facebook and Twitter.

Previous research identified a need to understand weather communication on a variety of platforms (Lazo et al. 2009). This research aimed to identify Twitter's place as a warning channel and continue a discussion about optimizing use of the platform. While it is not the top choice for weather information, it remains $a$ choice for receivers. The channel rankings found in this survey may assist in prioritizing distribution of information, but should not discourage use of any one channel. In fact, an increasingly diverse and mobile society will likely continue to use a multitude of channels to gather information, based on availability, convenience, type of weather, and other situational factors. Each channel arguably has advantages in different scenarios, so scholars should continue to work with practitioners to optimize communication on Twitter and all other channels available to information consumers.

\section{Conclusions}

Using Twitter as an example channel for delivery, this survey identified, in one geographic region, weather information channel preferences, desired content, and a weather warning format that generates response. While this, like many studies, came with limitations and ideas for further study, the results inspire three key recommendations, which are stated and parsed out in the following text.

Weather communication channels need to be examined not as a group but individually, and messages need to be tailored for each independently. Despite the cult interest in Twitter from weather and news types, Twitter is not as popular with the masses. Despite shortfalls from a communication perspective, Facebook has nearly quadruple the reach. Most important, to harness the power of Facebook as a communication channel, posts and included graphics especially must contain complete timestamps so to mitigate confusion once a weather product has become invalid or expired. Evidenced by the largest number of first-choice channel preference rankings in this survey, communicators also need to examine the challenges presented by mobile telephone apps. Understanding the types of information people 
desire and the proper way to communicate warnings may lend some insight to usage strategies for this newer channel.

Outreach regarding threats from all varieties of impact weather and associated terminology needs to remain a priority. Like with many consumer products, weather information that people claim to want and weather information to which people respond are two different things. While daily forecasts and photographs did not align in interest and response in this survey, watches and warnings generated both respondent interest and a reaction. This is a positive as watches and warnings are important weather products, but a negative in that all watches and warnings do not seem to be viewed equally. Tornado and severe thunderstorm products were of far greater interest to respondents than other threats, all of which can be deadly. However, flooding is more deadly than both of the aforementioned hazards. Perhaps better outreach is needed to make flood danger more salient. Recent flood disasters, such as Hurricane Harvey in Houston, Texas, and subsequent media attention may assist this effort.

Warning message transmission may seem ambiguous but communication and psychological literature underscore a need for standards to be developed in weather warning messages. Building on the block of weather warning awareness is the importance of format in these messages. Respondent reaction to minimally detailed warnings messages is troubling. Much like an ill patient would receive the best possible care from a medical professional, the average person will receive the best weather safety messaging from those in a related field. Weather communicators should focus less on analytics such as retweets, and more on the content being provided so that warnings are complete, personal, and actionable to the receiver. This should be an emphasis of major meteorological and disaster organizations such as the National Weather Service, the American Meteorological Society and the National Weather Association as the consequences are life and death.

\section{REFERENCES}

AMS, 2017: Best practices for publicly sharing weather information via social media. American Meteorological Society, accessed 15 September 2017, https://www.ametsoc.org/ams/index.cfm/ about-ams/ams-statements/statements-of-the-ams-in-force/ best-practices-for-publicly-sharing-weather-information-viasocial-media/.

Barnes, L. R., E. C. Gruntfest, M. H. Hayden, D. M. Schultz, and C. Benight, 2007: False alarms and close calls: A conceptual model of warning accuracy. Wea. Forecasting, 22, 1140-1147, https://doi.org/10.1175/WAF1031.1.

Bright, L. F., S. B. Kleiser, and S. L. Grau, 2015: Too much Facebook? An exploratory examination of social media fatigue. Comput. Human Behav., 44, 148-155, https://doi.org/ 10.1016/j.chb.2014.11.048.

Bruns, A., and J. Burgess, 2011: The use of Twitter hashtags in the formation of ad hoc publics. Sixth European Consortium for Political Research General Conference (ECPR 2011), Reykjavik, Iceland, European Consortium for Political Research, 1-9.

Bunting, J., and M. Muzio, 2014: First National Weather Association digital seals to mark an evolution in weather information delivery. National Weather Association Doc., 2 pp., http://nwas.org/wpcontent/uploads/2016/07/NWADigitalSealPressRelease.pdf.

Croasmun, J. T., and L. Ostrom, 2011: Using Likert-type scales in the social sciences. J. Adult Educ., 40 (1), 19-22, https:// files.eric.ed.gov/fulltext/EJ961998.pdf.

Demuth, J. L., J. K. Lazo, and R. E. Morss, 2012: Assessing and improving the NWS point-and-click webpage forecast information. NCAR/TN-493+STR, 373 pp., https://doi.org/10.5065/D6X92882.

Donner, W. R., H. Rodriguez, and W. Diaz, 2012: Tornado warnings in three southern states: A qualitative analysis of public response patterns. J. Homel. Secur. Emerg. Manage., 9 (2), https://doi.org/10.1515/1547-7355.1955.

Eachus, J., 2017: Weather communication on Twitter: Identifying popular content and optimal warning format via case studies and a survey analysis. Ph.D. dissertation, Louisiana State University, $159 \mathrm{pp}$., https://digitalcommons.lsu.edu/cgi/ viewcontent.cgi? article $=5138 \&$ context $=$ gradschool_dissertations.

Ferrell, J., 2012: Social media: A new horizon for forecasting. Weatherwise, 65, 12-18, https://doi.org/10.1080/00431672.2012.689584.

Gore, T. D., and C. C. Bracken, 2005: Testing the theoretical design of a health risk message: Reexamining the major tenets of the extended parallel process model. Health Educ. Behav., 32, $27-$ 41, https://doi.org/10.1177/1090198104266901.

Greenwood, S., A. Perrin, and M. Duggan, 2016: Social media update 2016. Pew Research Center Doc., 18 pp., http:// assets.pewresearch.org/wp-content/uploads/sites/14/2016/11/ 10132827/PI_2016.11.11_Social-Media-Update_FINAL.pdf.

Hoang, T. S., 2015: Blogging during a crisis: Threat and efficacy in online communication during a hurricane. Online J. Commun. Media Technol., 5 (2), 1-30.

Hong, L., O. Dan, and B. D. Davison, 2011: Predicting popular messages in Twitter. Proc. 20th Int. Conf. on World Wide Web $(W W W)$, Hyderabad, India, Assoc. for Computing Machinery, 57-58, https://doi.org/10.1145/1963192.1963222.

IEM, 2017: Archived NWS watch/warnings. Iowa Environmental Mesonet, accessed 26 October 2017, https://mesonet.agron.iastate.edu/ archive/.

Johnson, T. J., and B. K. Kaye, 2004: Wag the blog: How reliance on traditional media and the internet influence credibility perceptions of weblogs among blog users. J. Mass Commun. Quart., 81, 622-642, https://doi.org/10.1177/107769900408100310.

Kogan, M., L. Palen, and K. M. Anderson, 2015: Think local, retweet global: Retweeting by the geographically vulnerable during Hurricane Sandy. Proc. 18th ACM Conf. on Computer Supported Cooperative Work \& Social Computing, Vancouver, BC, Canada, Assoc. for Computing Machinery, 981-993, https:// doi.org/10.1145/2675133.2675218.

Lachlan, K. A., P. R. Spence, X. Lin, K. M. Najarian, and M. Del Greco, 2014: Twitter use during a weather event: Comparing content associated with localized and nonlocalized hashtags. Commun. Stud., 65, 519-534, https://doi.org/10.1080/ 10510974.2014.956940.

Lang, A., 2000: The limited capacity model of mediated message processing. J. Commun., 50, 46-70, https://doi.org/10.1111/ j.1460-2466.2000.tb02833.x. 
Lazo, J. K., R. E. Morss, and J. L. Demuth, 2009: 300 billion served: Sources, perceptions, uses, and values of weather forecasts. Bull. Amer. Meteor. Soc., 90, 785-798, https://doi.org/10.1175/ 2008BAMS2604.1.

Lindell, M. K., and R. W. Perry, 2012: The protective action decision model: Theoretical modifications and additional evidence. Risk Anal., 32, 616-632, https://doi.org/10.1111/ j.1539-6924.2011.01647.x.

MacDougall, R., 2005: Identity, electronic ethos, and blogs: A technologic analysis of symbolic exchange on the new news medium. Amer. Behav. Sci., 49, 575-599, https://doi.org/ 10.1177/0002764205280922.

Morss, R. E., J. K. Lazo, and J. L. Demuth, 2010: Examining the use of weather forecasts in decision scenarios: Results from a US survey with implications for uncertainty communication. Meteor. Appl., 17, 149-162, https://doi.org/10.1002/met.196.

NWS, 2016: Weather fatalities. National Weather Service, accessed 22 September 2017, http://www.nws.noaa.gov/om/hazstats.shtml.

Perreault, M. F., J. B. Houston, and L. Wilkins, 2014: Does scary matter?: Testing the effectiveness of new National Weather Service tornado warning messages. Commun. Stud., 65, 484 499, https://doi.org/10.1080/10510974.2014.956942.

Ripberger, J. T., H. C. Jenkins-Smith, C. L. Silva, D. E. Carlson, and M. Henderson, 2014: Social media and severe weather: Do tweets provide a valid indicator of public attention to severe weather risk communication? Wea. Climate Soc., 6, 520-520, https://doi.org/10.1175/WCAS-D-13-00028.1.

Romero, D. M., B. Meeder, and J. Kleinberg, 2011: Differences in the mechanics of information diffusion across topics: Idioms, political hashtags, and complex contagion on Twitter. Proc. 20th Int. Conf. on World Wide Web (WWW'11), Hyderabad, India, Assoc. for Computing Machinery, 695-704, https:// doi.org/10.1145/1963405.1963503.
Salinas, S., 2018: PEAK SOCIAL? The major social platforms are showing a significant slowdown in users. CNBC, 8 August 2018, https://www.cnbc.com/2018/08/08/social-media-activeusers-around-the-world.html.

Slovic, P., B. Fischhoff, and S. Lichtenstein, 1982: Why study risk perception? Risk Anal., 2, 83-93, https://doi.org/10.1111/ j.1539-6924.1982.tb01369.x.

St. Denis, L. A., K. M. Anderson, and L. Palen, 2014: Mastering social media: An analysis of Jefferson County's communications during the 2013 Colorado floods. 11th Int. Conf. on Information Systems for Crisis Response and Management (ISCRAM), University Park, Pennsylvania, Assoc. for Computing Machinery, 737-746.

Takahashi, B., E. C. Tandoc, and C. Carmichael, 2015: Communicating on Twitter during a disaster: An analysis of tweets during Typhoon Haiyan in the Philippines. Comput. Human Behav., 50, 392-398, https://doi.org/10.1016/ j.chb.2015.04.020.

Trainor, J., and S. McNeil, 2008: A brief summary of social science warning and response literature: A report to COT Netherlands. University of Delaware Disaster Research Center Misc. Rep. 62, 12 pp., http://udspace.udel.edu/handle/19716/ 4192\#files-area.

Verma, S., S. Vieweg, W. J. Corvey, L. Palen, J. H. Martin, M. Palmer, and K. M. Anderson, 2011: Natural language processing to the rescue? Extracting "Situational Awareness" tweets during mass emergency. Proceedings of the Fifth International AAAI Conference on Weblogs and Social Media, Barcelona, Spain, Assoc. for the Advancement of Artificial Intelligence, 385-392.

Witte, K., 1992: Putting the fear back into fear appeals: The extended parallel process model. Commun. Monogr., 59, 329349, https://doi.org/10.1080/03637759209376276. 